\title{
Administration of glycerol-based formulations in sheep results in similar ovulation rate to eCG but red blood cell indices may be affected
}

Cristian Porcu ${ }^{1 \dagger}$, Francesca D. Sotgiu ${ }^{1 \dagger}$, Valeria Pasciu' ${ }^{1}$, Maria Grazia Cappai , Alicia Barbero-Fernández², Antonio Gonzalez-Bulnes ${ }^{3}$, Maria Dattena ${ }^{4}$, Marilia Gallus ${ }^{4}$, Giovanni Molle ${ }^{4}$ and Fiammetta Berlinguer ${ }^{* *}$ (D)

\begin{abstract}
Background: The objective of this study was to investigate the metabolic and osmotic effects of different doses of glycerol or a glycerol - propylene glycol mixture in Sarda sheep with the aim to identify those able to beneficially modify ewe's metabolic status without harmful changes in red blood cell (RBC) indices. Thereafter, the selected doses were tested for their effects on ewe's ovarian activity during an induced follicular phase and compared to the effects of a hormonal treatment with equine chorionic gonadotrophin (eCG).

Results: Glycerol was administered alone (G groups: $90 \%$ glycerol and $10 \%$ water; $\% \mathrm{v} / \mathrm{v}$ ) or in combination with propylene glycol (M groups: 70\% glycerol, 20\% propylene glycol, 10\% water; $\% \mathrm{v} / \mathrm{v}$ ). Treatments were formulated to provide 100, 75, 50 and 25\% of the amount of energy supplied in previous experiments. Obtained results showed that the formulations G75 and M75 (22.5 and 18.2\% on DM basis, respectively) induce metabolic changes comparable to those induced by $\mathrm{M} 100$. The latter dose has been already evaluated for its effects on sheep metabolism and reproductive performance. However, with these high doses, plasma osmolality increased significantly, and RBC indices showed significant alterations. The low dose groups (G25 and M25, 8.6 and 6.9\% on DM basis, respectively) did not show any alterations in plasma osmolality and RBC indices, but the metabolic milieu differed markedly from that of M100. Between the medium dose groups, M50 (12.9\% on DM basis) showed a more comparable milieu to M100 than G50 (15.9\% on DM basis) and no RBC alterations. Therefore, M75, G75 and M50 doses were tested for their effect on ovarian functions and proved to be equally effective as eCG.
\end{abstract}

Conclusion: The results of the present study evidenced an alteration of RBC indices, and possibly of their functions, as a side effect of glycerol administration at high doses in the diet of ewes. Therefore, protocols foreseeing the administration of glycerol should be tested for their effects on RBC indices and functions. In general terms, the medium dose of the glucogenic mixture (12.9\% of dietary DM on offer) should be preferred.

Keywords: Propylene glycol, Ovary, Insulin, Glucose, NEFA, Urea, Plasma osmolality, Red blood cells

\footnotetext{
*Correspondence: berling@uniss.it

${ }^{+}$Cristian Porcu and Francesca D. Sotgiu contributed equally to this work.

'Department of Veterinary Medicine, University of Sassari, Via Vienna 2, 07100 Sassari, Italy

Full list of author information is available at the end of the article
}

(c) The Author(s). 2020 Open Access This article is licensed under a Creative Commons Attribution 4.0 International License, which permits use, sharing, adaptation, distribution and reproduction in any medium or format, as long as you give appropriate credit to the original author(s) and the source, provide a link to the Creative Commons licence, and indicate if changes were made. The images or other third party material in this article are included in the article's Creative Commons licence, unless indicated otherwise in a credit line to the material. If material is not included in the article's Creative Commons licence and your intended use is not permitted by statutory regulation or exceeds the permitted use, you will need to obtain permission directly from the copyright holder. To view a copy of this licence, visit http://creativecommons.org/licenses/by/4.0/. The Creative Commons Public Domain Dedication waiver (http://creativecommons.org/publicdomain/zero/1.0/) applies to the data made available in this article, unless otherwise stated in a credit line to the data. 


\section{Background}

By-products sourced from plant crops represent an important human-inedible feed resource for livestock production [1]. These waste streams can source from different agro-industrial processes, and their use as feed ingredient or feed supplement can contribute to the environmental sustainability of livestock sectors. Recently, there has been an increasing global demand for biofuels, resulting in an increased demand for the feedstuffs (corn, wheat, and oilseeds) used for fuel extraction. The main by-product during the production of biodiesel is glycerol, which can be used as livestock feed ingredient or feed supplement [2]. The EU legislation approved glycerol and another biodiesel co-product, namely propylene glycol, as animal feed additives with no restrictions on animal species or quantity that may be fed, while recommending from the European Food Safety Authority the collection of data on the presence of impurities and contaminants in crude glycerine from biodiesel production $[3,4]$.

In small ruminants, glycerol, alone or in association with propylene glycol, has been used both as replacer of corn grain in the diet [5-9] and as a feed supplement to increase productive performance [10-17]. In these studies, glycerol was supplemented at a percentage of inclusion on dry matter (DM) basis ranging from $3 \%$ up to $45 \%$. Overall the metabolic effects described include an increase in glucose and a decrease in NEFA circulating concentrations $[6,11,18]$. Other studies in ewes also reported an increase in insulin [19-21], insulin-like growth factor-1 [20], and a decrease in urea circulating concentrations $[20,21]$ after oral administration of $280 \mathrm{~mL}$ gly-

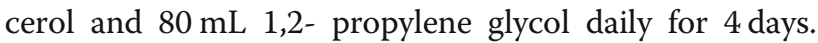
These changes have been associated with changes in follicular fluid composition during treatment period [20], and may contribute in creating a suitable systemic and local metabolic milieu for the promotion of ovarian function. Glucogenic mixtures based on glycerol, administered as short-term flushing can indeed increase ovulation rate [19] and oocyte quality [10] in sheep. The increase in ovulation rate following glycerol administration has been described also in other studies in which glycerol was administered in a single dose [14, 15]. Therefore, a short or very short (daily) flushing based on glycerol can represent a valid alternative to other short flushing techniques based on conventional feedstuff such lupin seeds [22] or soybean meal [23, 24]. Moreover, thanks to its boosting activity on ovarian functions, glycerol could possibly substitute for synthetic gonadotropins dosed to increase lambing and twinning rates in sheep. Among them, it is noteworthy the equine chorionic gonadotropin (eCG), a hormone commonly used in concert with progestogen to induce ovulation prior to natural mating or artificial insemination. The future use and availability of eCG appears to be strongly challenged by highly active animal-rights movement because the hormone is obtained from pregnant mares. Hence, there is a need for alternative synchronization protocols without eCG [25].

Although there is evidence that glycerol and glucogenic mixtures can improve production and reproductive performance in sheep, these additives may sometimes negatively impact on animal welfare, at least under some circumstances. In fact, after oral administration, a significant proportion of glycerol (44\% according to [26]) is rapidly absorbed through rumen wall by passive diffusion and transported via the bloodstream to serve directly as a substrate for glucose synthesis in the liver [27, 28]. In a previous study [21], we reported that the administration of a glycerol-based formulation $(280 \mathrm{~mL}$ glycerol and $80 \mathrm{~mL}$ propylene glycol for 4 days; $23 \%$ DM) caused a 400 -folds increase in circulating glycerol concentration in dairy ewes. Unfortunately, glycerol is a hyperosmotic agent and, consequently, plasma osmolality was greatly increased [21]. This effect had been already observed in humans [29-31]. Glycerol can readily permeate the red blood cells (RBCs) membrane at body temperature following a concentration gradient [32]. Both the increase in plasma osmolality [33] and glycerol diffusion in the RBCs [34] can impact on cellular volume homeostasis which is critical for erythrocyte survival [35]. Changes in RBCs volume can affect their membrane integrity, leading to impaired functionality and increased eryptosis [36, 37]. The critical importance of $\mathrm{RBC}$ volume regulation is demonstrated by several pathologies resulting from either overhydration or dehydration of RBCs [33].

Thus, the objective of this study was to investigate the metabolic and osmotic effects of different doses of glycerol and glycerol - propylene glycol mixtures in Sarda sheep in order to identify those able to positively modify ewe's metabolic status without significantly affecting $\mathrm{RBC}$ indices. The highest dose of the glucogenic mixture was taken from previous studies, being already evaluated for its effects on sheep metabolism and reproductive performance $[8,16,18]$. Thereafter, to determine the ability of the selected glucogenic doses to promote ovarian function, we evaluated their effects on ewe's ovarian activity during an induced follicular phase, comparing them to the effects of the administration of a synthetic gonadotropin (eCG).

\section{Results}

Phase 1

Body weight did not change after the administration of the dietary treatments and no differences were observed between groups (M100 51.6 \pm 1.7, G100 53.8 \pm 3 , M75 $51.6 \pm 2.1$, G75 50.3 \pm 1.8 , M50 $48.7 \pm 1.9$, G50 48.1 \pm 1.8 , M25 50.1 \pm 1.8 , G25 50.6 $\pm 3.8 ; P>0.05)$. 
Before starting the titration feeding treatments, plasma osmolality, RBC indices, circulating concentrations of analysed metabolites and hormones were within the physiological ranges for the species [38] in all the ewes showing no differences between groups (D 0; Table 1).

To evaluate the osmotic effect of glycerol rise in the bloodstream, we assessed the changes in plasma osmolality and RBC indices among the different groups before and $2 \mathrm{~h}$ after glucogenic formulations administration. Pearson's correlation analyses showed that the moles of glycerol and propylene glycol administered daily showed a moderately strong direct correlation $(\mathrm{r}=0.668 ; p<$ 0.001 ) with plasma osmolality (Table 2 ).

The administration of the glucogenic formulations determined indeed a significant increase in plasma osmolality in the high and moderate dose groups (M100, G100, M75, G75; p < 0.001). In these latter groups peak values were significantly higher than those recorded in the medium (M50 and G50) and low (M25 and G25;) dose groups $(p<0.05$, Table 3$)$.

$\mathrm{RBC}$ indices and their variations after treatment are shown in Table 4. The absence of microscopic platelet clumping or $\mathrm{RBC}$ agglutination or roulaux formation in whole blood smears allowed to consider blood samples processed at automatic cell counter as diagnostic for the purposes of this investigation. It is to point out that the absence of roulaux bodies may also have a diagnostic indication for particular conditions, including erythrocyte sedimentation rate (ESR) which may occur in the presence of an inflammatory condition, for instance, despite it is consolidated that the two parameters may not be strictly proportional [39]. In view of the diagnostic aspects, all animals enrolled appeared clinically healthy throughout the trial.

Compared to pre-administration values, no changes in RBC indices were found in M25, G25 and M50 groups, while in G50 a significant decrease in mean cell haemoglobin concentration (MCHC) was found. In the high and moderate dose groups (M100, G100, M75, G75), the significant decrease in $\mathrm{MCHC}$ was accompanied by a significant increase in mean cell volume (MCV) and RBC distribution width (RDW-SD; Table 4). Representative pictures of the $\mathrm{RBC}$ shape alterations found in the high dose group $2 \mathrm{~h}$ after treatment administrations are shown in Fig. 1.

In line with these results, Pearson's correlation analyses showed that the moles of glycerol and propylene glycol administered daily were directly correlated with RDW-SD $(\mathrm{r}=0.539 ; p<0.001)$ and MCV $(\mathrm{r}=0.495 ; \mathrm{p}<$ $0.001)$ and indirectly correlated with $\mathrm{MCHC}(\mathrm{r}=0.582$; $\mathrm{p}<0.001$; Table 5). It should be pointed out that in all the groups but M100 these alterations were not observed in blood samples collected on the D 3 before glucogenic mixture administration, i.e., after $12 \mathrm{~h}$ from the last administration (Table 2).

It should be pointed out that in all the groups but M100 these alterations were not observed in blood samples collected on the D 3 before glucogenic mixture administration, i.e., after $12 \mathrm{~h}$ from the previous administration (Table 1). To identify the formulations and doses capable to induce a positive change in ewe's metabolic status we assessed their effects against those induced

Table 1 Plasma osmolality, RBC indices and circulating concentrations of analysed metabolites and hormones

\begin{tabular}{|c|c|c|c|c|c|c|c|c|c|c|c|c|c|}
\hline Group & Day & OSMOL/kg & $\begin{array}{l}\text { MCV } \\
(\mathrm{fL})\end{array}$ & $\begin{array}{l}\mathrm{MCH} \\
(\mathrm{pg})\end{array}$ & $\begin{array}{l}\mathrm{MCHC} \\
(\mathrm{g} / \mathrm{L})\end{array}$ & $\begin{array}{l}\text { RDW-Sd } \\
\text { (fL) }\end{array}$ & $\begin{array}{l}\text { GLUCOSE } \\
\mathrm{mg} / \mathrm{dL}\end{array}$ & $\begin{array}{l}\text { UREA } \\
\mathrm{mg} / \mathrm{dL}\end{array}$ & & $\begin{array}{l}\text { NEFA } \\
\mathrm{Mmol} / \mathrm{L}\end{array}$ & & $\begin{array}{l}\text { INSULIN } \\
\mu \mathrm{g} / \mathrm{L}\end{array}$ & $\begin{array}{l}\text { GLYCEROL } \\
\mathrm{mg} / \mathrm{dL}\end{array}$ \\
\hline M100 & D0 & $0.317 \pm 0.002$ & $34.50 \pm 0.78$ & $11.24 \pm 0.27$ & $313.00 \pm 2.93$ & a $\quad 28.48 \pm 0.78$ & $55.94 \pm 3.52$ & $21.65 \pm 2.20$ & & $0.14 \pm 0.01$ & & $0.28 \pm 0.06$ & $0.09 \pm 0.03$ \\
\hline M100 & D3 & $0.316 \pm 0.001$ & $34.36 \pm 0.78$ & $11.12 \pm 0.23$ & $324.40 \pm 2.56$ & $28.32 \pm 0.84$ & $63.96 \pm 4.59$ & $13.92 \pm 2.10$ & & $0.06 \pm 0.01$ & & $0.40 \pm 0.07$ & $0.05 \pm 0.00$ \\
\hline G100 & D0 & $0.317 \pm 0.003$ & $36.22 \pm 0.91$ & $11.40 \pm 0.27$ & $314.80 \pm 2.65$ & $30.60 \pm 0.70$ & $49.42 \pm 1.25$ & $24.10 \pm 2.58$ & $a$ & $0.11 \pm 0.05$ & & $0.50 \pm 0.05$ & $0.14 \pm 0.04$ \\
\hline G100 & D3 & $0.318 \pm 0.005$ & $36.02 \pm 0.86$ & $11.50 \pm 0.29$ & $319.60 \pm 6.04$ & $30.34 \pm 0.61$ & $55.23 \pm 2.59$ & $12.38 \pm 1.45$ & & $0.05 \pm 0.02$ & & $0.66 \pm 0.11$ & $0.13 \pm 0.05$ \\
\hline M75 & D0 & $0.275 \pm 0.035$ & $35.88 \pm 1.32$ & $11.30 \pm 0.30$ & $303.60 \pm 5.00$ & $31.22 \pm 1.18$ & $52.63 \pm 3.73$ & $25.58 \pm 1.75$ & $a$ & $0.18 \pm 0.08$ & & $0.52 \pm 0.04$ & $0.20 \pm 0.08$ \\
\hline M75 & D3 & $0.315 \pm 0.003$ & $37.24 \pm 1.11$ & $11.36 \pm 0.29$ & $304.80 \pm 6.26$ & $30.62 \pm 1.20$ & $59.30 \pm 2.47$ & $12.87 \pm 0.80$ & & $0.02 \pm 0.00$ & & $0.70 \pm 0.19$ & $0.19 \pm 0.12$ \\
\hline G75 & D0 & $0.308 \pm 0.004$ & $33.44 \pm 1.11$ & $10.48 \pm 0.33$ & $311.20 \pm 2.78$ & $28.06 \pm 1.07$ & $52.28 \pm 1.36$ & $22.07 \pm 0.61$ & 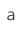 & $0.31 \pm 0.05$ & & $0.56 \pm 0.11$ & $0.16 \pm 0.04$ \\
\hline G75 & D3 & $0.309 \pm 0.003$ & $33.44 \pm 1.11$ & $10.42 \pm 0.34$ & $311.40 \pm 2.87$ & $27.96 \pm 1.01$ & $53.23 \pm 4.19$ & $10.95 \pm 1.38$ & & $0.04 \pm 0.01$ & & $0.72 \pm 0.18$ & $0.17 \pm 0.07$ \\
\hline M50 & Do & $0.300 \pm 0.000$ & $35.84 \pm 1.32$ & $11.44 \pm 0.25$ & $305.60 \pm 6.65$ & $31.44 \pm 1.34$ & $52.16 \pm 2.21$ & $26.80 \pm 2.08$ & $a$ & $0.15 \pm 0.05$ & a & $0.32 \pm 0.08$ & $0.23 \pm 0.07$ \\
\hline M50 & D3 & $0.302 \pm 0.001$ & $37.32 \pm 1.09$ & $11.44 \pm 0.29$ & $307.00 \pm 5.43$ & $31.42 \pm 1.29$ & $57.56 \pm 1.13$ & $17.06 \pm 1.38$ & & $0.03 \pm 0.01$ & & $0.40 \pm 0.09$ & $0.10 \pm 0.03$ \\
\hline G50 & D0 & $0.311 \pm 0.007$ & $33.58 \pm 0.85$ & $10.48 \pm 0.32$ & $312.00 \pm 2.35$ & $27.50 \pm 0.99$ & $42.43 \pm 7.01$ & $29.19 \pm 2.02$ & & $0.12 \pm 0.02$ & & $0.47 \pm 0.12$ & $0.38 \pm 0.08$ \\
\hline G50 & D3 & $0.304 \pm 0.016$ & $33.34 \pm 0.80$ & $10.36 \pm 0.30$ & $310.60 \pm 2.82$ & $27.76 \pm 0.98$ & $53.33 \pm 2.36$ & $18.32 \pm 1.22$ & & $0.05 \pm 0.03$ & & $0.50 \pm 0.16$ & $0.17 \pm 0.06$ \\
\hline M25 & D0 & $0.311 \pm 0.003$ & $34.66 \pm 0.88$ & $10.86 \pm 0.22$ & $313.00 \pm 2.93$ & $29.24 \pm 1.01$ & $55.94 \pm 3.52$ & $21.65 \pm 2.20$ & & $0.23 \pm 0.06$ & & $0.27 \pm 0.06$ & $0.12 \pm 0.07$ \\
\hline M25 & D3 & $0.317 \pm 0.004$ & $34.70 \pm 0.84$ & $11.02 \pm 0.28$ & $318.20 \pm 2.52$ & $29.34 \pm 0.99$ & $46.19 \pm 3.52$ & $16.54 \pm 2.59$ & & $0.18 \pm 0.03$ & & $0.33 \pm 0.08$ & $0.06 \pm 0.02$ \\
\hline G25 & D0 & $0.307 \pm 0.001$ & $36.50 \pm 0.82$ & $11.36 \pm 0.20$ & $311.80 \pm 3.40$ & $29.96 \pm 1.01$ & $48.26 \pm 2.03$ & $24.10 \pm 2.58$ & & $0.25 \pm 0.08$ & & $0.32 \pm 0.11$ & $0.10 \pm 0.05$ \\
\hline G25 & D3 & $0.306 \pm 0.002$ & $36.76 \pm 0.87$ & $11.36 \pm 0.18$ & $309.60 \pm 3.61$ & $30.50 \pm 1.13$ & $50.44 \pm 2.74$ & $20.28 \pm 3.04$ & & $0.04 \pm 0.01$ & & $0.33 \pm 0.08$ & $0.28 \pm 0.18$ \\
\hline
\end{tabular}

a Letters indicate significant differences between D 0 and D 3 (before glycerol-based formulation administration) within the same group; $p<0.05$ 
Table 2 Pearson correlation coefficients between moles of glucogenic compounds administered, osmolarity, metabolites and hormones

\begin{tabular}{|c|c|c|c|c|c|c|}
\hline & Moles of glycerol + propylene glycol & Plasma osmolality & Glycerol (mg/dL) & Glucose (mg/dL) & Insulin $(\mu \mathrm{g} / \mathrm{L})$ & UREA (mg/dL) \\
\hline Plasma osmolality & $0.668(<0.001)$ & & & & & \\
\hline Glycerol (mg/dL) & $0.592(<0.001)$ & $0.830(<0.001)$ & & & & \\
\hline Glucose (mg/dL) & $0.352(<0.001)$ & $0.491(<0.001)$ & $0.493(<0.001)$ & & & \\
\hline Insulin ( $\mu \mathrm{g} / \mathrm{L})$ & $0.416(<0.001)$ & $0.308(<0.001)$ & $0.328(<0.001)$ & $\begin{array}{l}0.425 \\
(<0.001)\end{array}$ & & \\
\hline UREA (mg/dL) & $-0.574(<0.001)$ & $-0.357(<0.001)$ & $-0.328(<0.001)$ & $-0.300(<0.001)$ & $-0.452(<0.001)$ & \\
\hline NEFA (mmol/L) & $-0.416(<0.001)$ & $-0.304(<0.001)$ & $-0.325(<0.001)$ & $-0.226(<0.001)$ & $-0.352(<0.001)$ & $0.175(<0.01)$ \\
\hline
\end{tabular}

Corresponding $P$-values are shown within parenthesis

by M100. The latter dose has been indeed already evaluated for its effects on sheep metabolism and reproductive performance $[8,16,18]$. Obtained results shows that the high and moderate dose groups (G100, M75 and G75) showed no differences in mean glycerol plasma concentrations compared to the M100 one (Fig. 2a). Consequently, no differences were found between those groups and M100 in the circulating concentrations of glucose, insulin, urea and NEFA (Fig. 2b,c,d,e). Pearson's correlation analyses showed indeed that the moles of glycerol and propylene glycol administered daily showed a fair direct correlation with glycerol, glucose, insulin and NEFA circulating concentration $(r=0.592 ; p<$ 0.001 ) and a fair indirect correlation with urea circulating concentration $(\mathrm{r}=0.574 ; \mathrm{p}<0.001$; Table 2).

In line with this results, the G50 and low dose groups (M25, G25) showed lower mean glycerol concentrations compared to $\mathrm{M} 100$, and consequently differed from M100 in the mean concentrations of glucose, insulin, and urea (Fig. 2b,d). It is noteworthy that M50, while differing from M100 in glycerol, glucose and urea mean concentrations, showed no difference in mean insulin concentrations (Fig. 2c). NEFA mean concentrations were higher than those found in M100 only in the low dose groups. Supplementary Figure 1 shows the concentrationstime data of the analysed metabolites and hormones.

Taken together, results show that the formulations M75 and G75 are able to induce metabolic changes comparable to those induced by M100. Hence, the dose of the glucogenic formulation can be lowered from 23 to $18 \%$ of diet on DM basis, without apparently inducing any significant change in ewe's metabolic response. However, with these moderate doses, plasma osmolality increased significantly, and RBC indices showed significant variations. Between the medium dose group, M50 showed lower glucose and higher urea mean concentrations than M100. However, insulin and NEFA mean concentrations did not differ from those found in the M100 group. Moreover, the M50 group did not show any significant variations in plasma osmolality and $\mathrm{RBC}$ indices thus suggesting that glycerol osmotic effects were less marked than in the high and moderate dose groups.

Therefore, the glucogenic doses selected to determine the promotion of ovarian function (phase 2 of the present study) turned out to be M75, G75 and M50.

\section{Phase 2}

As in the previous phase, body weight did not change after the administration of the feeding treatments and no differences were observed between groups (M75 $42.3 \pm 1.7$, G75 $42.4 \pm 1.8$, M50 $44.4 \pm 1.8$, GON $42.1 \pm$ $3.5 ; P>0.05)$.

The number of follicles ranged between 1 to $3 \mathrm{~mm}$ in diameter, ovarian volume $(\mathrm{mL})$, vascularity index, flow index and their relationship (Table 6) did not show any differences between groups. The number of large follicles (4 to $7 \mathrm{~mm}$ in diameter), however, was higher in the M75 group compared to the GON group $(\mathrm{P}=<0.05$; Table 6), while no differences were found between the other groups.

On the other hand, no differences were found between groups in oestradiol concentrations on Day 5 of experimental period (M50 $16.2 \pm 1.9 \mathrm{pg} / \mathrm{mL} ; \mathrm{M} 7512.6 \pm 1.9 \mathrm{pg} / \mathrm{mL}$; G75 $14.8 \pm 1.9 \mathrm{pg} / \mathrm{mL} ;$ eCG $12.1 \pm 2.1 \mathrm{pg} / \mathrm{mL} ; P=0.414)$. Finally, ovulation rate in M75 was equal to eCG (1.4 \pm 0.2 for both) and even numerically higher in G75 and M50 (1.6 \pm 0.2 and $2.0 \pm 0.2$, respectively), although differences were not statistically significant.

\section{Discussion}

The results of the present study showed, for the first time, that the administration of glycerol-based glucogenic formulations causes significant changes in RBC indices of ewes with a dose-related effect. When the glucogenic formulations were administered at a percentage of inclusion on DM basis ranging from 18.2 to $27.4 \%$, these changes indicated an increase in $\mathrm{RBC}$ volume $(\mathrm{MCV})$, which was associated with a variation in the size of the erythrocytes (increased RDW-SD) and with a dilution in the amount of haemoglobin per volume unit 


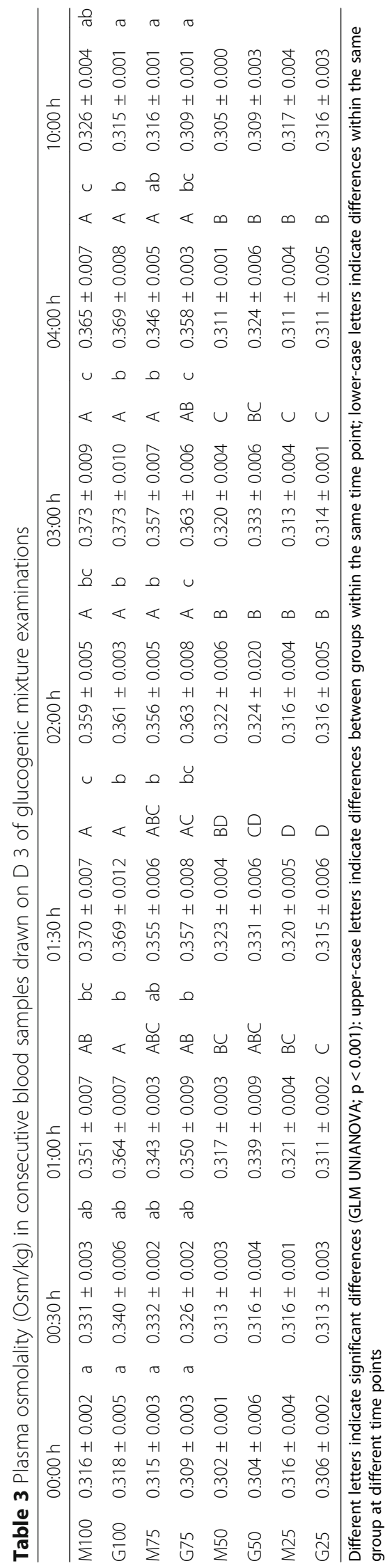


Table 4 RBC indices in two consecutive blood samples drawn before and $2 \mathrm{~h}$ after glucogenic administration

\begin{tabular}{|c|c|c|c|c|c|c|c|c|}
\hline & SAMPLE TIME & MCV (fL) & & $\mathrm{MCH}(\mathrm{pg})$ & $\mathrm{MCHC}(\mathrm{g} / \mathrm{L})$ & & RDW-SD (fL) & \\
\hline \multirow[t]{2}{*}{ M100 } & $00: 00 \mathrm{~h}$ & $34.36 \pm 0.78$ & $* *$ & $11.12 \pm 0.23$ & $324.40 \pm 2.56$ & $* *$ & $28.32 \pm 0.84$ & * \\
\hline & $02: 00 \mathrm{~h}$ & $37.86 \pm 0.58$ & & $11.20 \pm 0.21$ & $296.00 \pm 5.74$ & & $32.24 \pm 1.20$ & \\
\hline \multirow[t]{2}{*}{ G100 } & $00: 00 \mathrm{~h}$ & $36.02 \pm 0.86$ & * & $11.50 \pm 0.29$ & $319.60 \pm 6.04$ & * & $30.34 \pm 0.61$ & * \\
\hline & $02: 00 h$ & $41.74 \pm 1.55$ & & $11.58 \pm 0.28$ & $278.80 \pm 11.3$ & & $37.06 \pm 2.00$ & \\
\hline \multirow[t]{2}{*}{ M75 } & $00: 00 \mathrm{~h}$ & $37.24 \pm 1.11$ & * & $11.36 \pm 0.29$ & $304.80 \pm 6.26$ & * & $30.62 \pm 1.20$ & * \\
\hline & $02: 00 \mathrm{~h}$ & $41.02 \pm 1.10$ & & $11.46 \pm 0.27$ & $279.20 \pm 7.29$ & & $35.48 \pm 1.24$ & \\
\hline \multirow[t]{2}{*}{ G75 } & $00: 00 \mathrm{~h}$ & $33.44 \pm 1.11$ & * & $10.42 \pm 0.34$ & $311.40 \pm 2.87$ & $* * *$ & $27.96 \pm 1.01$ & * \\
\hline & $02: 00 \mathrm{~h}$ & $38.22 \pm 1.47$ & & $10.60 \pm 0.37$ & $277.60 \pm 3.08$ & & $33.86 \pm 1.62$ & \\
\hline \multirow[t]{2}{*}{ M50 } & $00: 00 \mathrm{~h}$ & $37.32 \pm 1.09$ & & $11.44 \pm 0.29$ & $307.00 \pm 5.43$ & & $31.42 \pm 1.29$ & \\
\hline & $02: 00 \mathrm{~h}$ & $38.70 \pm 0.84$ & & $11.40 \pm 0.22$ & $294.40 \pm 4.64$ & & $33.36 \pm 1.18$ & \\
\hline \multirow[t]{2}{*}{ G50 } & $00: 00 \mathrm{~h}$ & $33.34 \pm 0.80$ & & $10.36 \pm 0.30$ & $310.60 \pm 2.82$ & * & $27.76 \pm 0.98$ & \\
\hline & $02: 00 \mathrm{~h}$ & $35.70 \pm 1.37$ & & $10.42 \pm 0.32$ & $292.00 \pm 3.56$ & & $29.38 \pm 0.32$ & \\
\hline \multirow[t]{2}{*}{ M25 } & $00: 00 \mathrm{~h}$ & $34.70 \pm 0.84$ & & $11.02 \pm 0.28$ & $318.20 \pm 2.52$ & & $29.34 \pm 0.99$ & \\
\hline & $02: 00 h$ & $34.98 \pm 0.80$ & & $10.90 \pm 0.22$ & $311.60 \pm 1.78$ & & $29.22 \pm 0.93$ & \\
\hline \multirow[t]{2}{*}{ G25 } & $00: 00 \mathrm{~h}$ & $36.76 \pm 0.87$ & & $11.36 \pm 0.18$ & $309.60 \pm 3.61$ & & $30.50 \pm 1.13$ & \\
\hline & $02: 00 \mathrm{~h}$ & $37.00 \pm 0.51$ & & $11.42 \pm 0.32$ & $308.80 \pm 3.53$ & & $30.50 \pm 0.55$ & \\
\hline
\end{tabular}

00:00 h: immediately before the morning administration of glucogenic mixture. MCV: defines the size of the red blood cells and is expressed as femtoliters (10 ${ }^{-15}$; $\mathrm{fl}$ ); $\mathrm{MCH}$ : quantifies the amount of haemoglobin per red blood cell and is expressed in picograms (pg); MCHC: indicates the amount of haemoglobin per unit volume and it is expressed as g/L of RBCs; RDW-SD: represents the coefficient of variation of the RBC volume distribution (size) and is expressed as femtoliters ${ }^{*}$ Asterisks indicate significant differences within the same group between time 00.00 and time $02.00:{ }^{*} p<0.05 ;{ }^{* *} p<0.01 ;{ }^{* * *} p<0.001$

(decreased $\mathrm{MCHC}$ ). In the high and moderate dose groups the RBC shape alterations were found $2 \mathrm{~h}$ after the administration of glucogenic formulation administration when glycerol concentrations in the bloodstream were higher than $\approx 200 \mathrm{mg} / \mathrm{dL}$. This rise was also associated with a significant increase in plasma osmolality, as already reported in lactating ewes when the glycogenic formulation was given at $23 \%$ of inclusion on DM basis [21]. When the glycerol formulations were administered at lower doses (G50, 15.9\% DM) a significant decrease in MCHC was the sole alteration observed. Below such value $(\leq 12.9 \% \mathrm{DM}$;

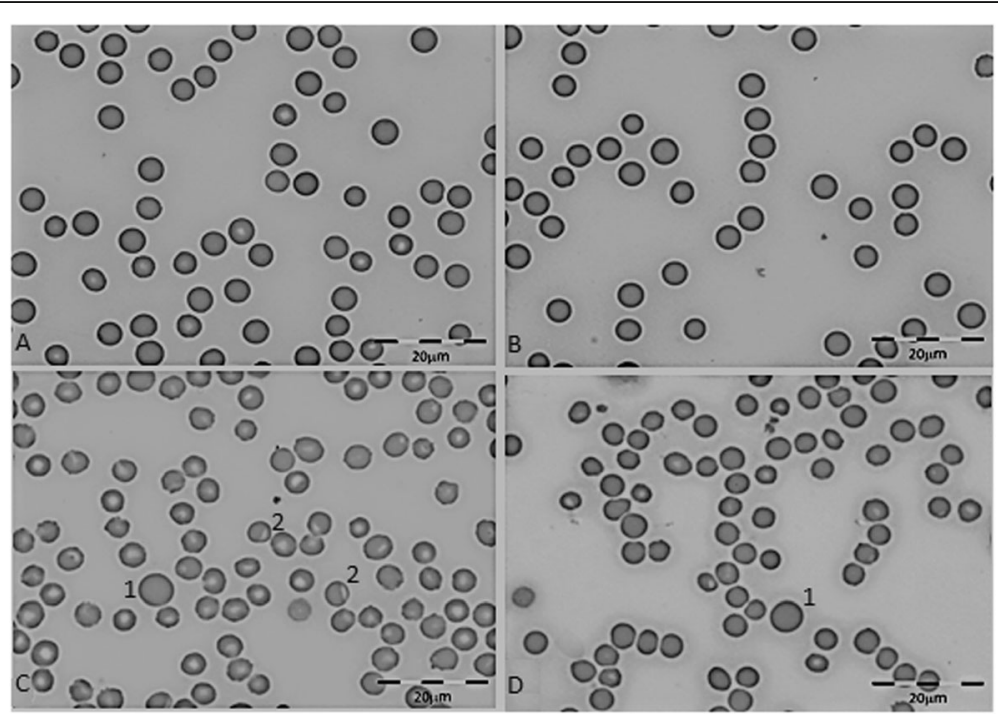

Fig. 1 Representative images of RBC shape alterations observed in the high (M100 and G 100) and moderate dose (M75 and G75) groups. Panel $\mathbf{a}$ and $\mathbf{b}$ shows normal erythrocytes. Panel $\mathbf{c}$ show erythrocytes anisocytosis, macrocytosis (C-1), eccentrocyte (C-2) (hemoglobin halo is moved on one side showing oxidative damage). Panel $D$, erythrocytes anisocytosis, macrocytosis (D-1) 
Table 5 Pearson correlation coefficients between the moles of glucogenic compounds administered and RBC indices

\begin{tabular}{|c|c|c|c|c|}
\hline & Moles of glycerol + propylene glycol & MCV (fL) & $\mathrm{MCH}(\mathrm{pg})$ & $\mathrm{MCHC}(\mathrm{g} / \mathrm{L})$ \\
\hline $\mathrm{MCV}(\mathrm{fL})$ & $0.495(<0.001)$ & & & \\
\hline MCH (pg) & $0.092(0.573)$ & $0.671(<0.001)$ & & \\
\hline $\mathrm{MCHC}(\mathrm{g} / \mathrm{L})$ & $-0.582(<0.001)$ & $-0.675(<0.001)$ & $0.089(0.586)$ & \\
\hline RDW-SD (fL) & $0.539(<0.001)$ & $0.846(<0.001)$ & $0.327(<0.05)$ & $-0.809(<0.001)$ \\
\hline
\end{tabular}

Corresponding $P$-values are shown within parenthesis

M50, M25 and G25), no significant alterations in $\mathrm{RBC}$ indices were found.

Glycerol is lipid soluble so it can diffuse by simple diffusion directly through the RBC membrane following a concentration gradient [32]. It is known that glycerol enters human RBCs by two pathways: facilitated diffusion through aquaporins, and simple diffusion [40, 41]. By contrast, glycerol is transported in sheep $\mathrm{RBC}$ via simple diffusion only $[41,42]$, and hence it has a lower permeability coefficient compared to humans [43]. In humans, the effects of glycerol permeation on $\mathrm{RBC}$ functionality have been described in in vitro studies focusing on $\mathrm{RBC}$ cryopreservation, where glycerol is used as penetrating cryoprotectant [44]. It has been reported that glycerol permeation in the RBC membrane resulted in shape alterations (increased MCV and RDW-SD) which appeared to be closely related to membrane alterations, increased permeability to ions and increased osmotic fragility [45]. These results are confirmed by another study in which the glycerol- dependent shape alterations

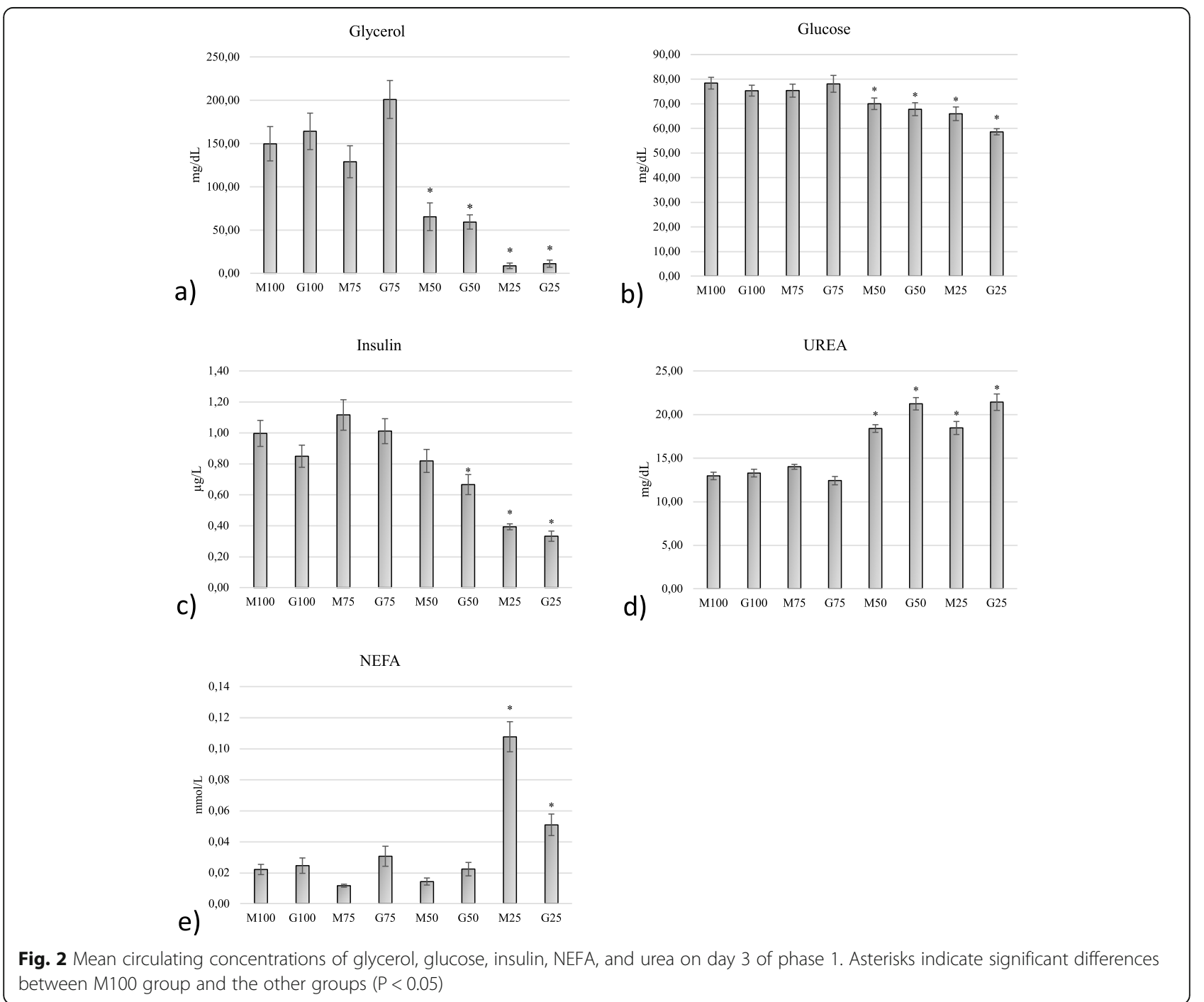


Table 6 Number of follicles, vascularity and flow index, their relationship and ovulation rate

\begin{tabular}{|c|c|c|c|c|c|c|c|c|}
\hline Groups & Days & 1-3 mm Follicles & 4-7 mm Follicles & VOML & $\mathrm{VIO}$ & $\mathrm{FIO}$ & VFIO & Ovulation Rate (day 15) \\
\hline \multirow[t]{4}{*}{ M75 } & 1 & $2.7 \pm 0.7$ & $3.0 \pm 0.6$ & $1.4 \pm 0.1$ & $2.5 \pm 4.8$ & $30.3 \pm 3.2$ & $8.2 \pm 2.4$ & $1.4 \pm 0.2$ \\
\hline & 2 & $4.0 \pm 0.0$ & $2.7 \pm 0.9$ & $1.4 \pm 0.2$ & $26.4 \pm 6.1$ & $30.2 \pm 3.5$ & $9.0 \pm 2.5$ & \\
\hline & 3 & $4.3 \pm 0.3$ & $2.3 \pm 0.3$ & $1.0 \pm 0.1$ & $31.9 \pm 5.7$ & $26.8 \pm 2.1$ & $9.3 \pm 1.9$ & \\
\hline & 4 & $4.8 \pm 0.7$ & $2.6 \pm 0.5^{\mathrm{A}, \mathrm{B}}$ & $0.9 \pm 0.2$ & $24.4 \pm 10.3$ & $27.5 \pm 5.6$ & $9.2 \pm 5.1$ & \\
\hline \multirow[t]{4}{*}{ G75 } & 1 & $4.0 \pm 0.8$ & $2.5 \pm 0.5$ & $1.7 \pm 0.6$ & $19.0 \pm 3.9$ & $28.3 \pm 5.9$ & $6.5 \pm 2.5$ & $1.6 \pm 0.2$ \\
\hline & 2 & $4.8 \pm 0.9$ & $2.5 \pm 0.6$ & $2.4 \pm 0.6$ & $29.5 \pm 5.0$ & $31.6 \pm 1.6$ & $9.4 \pm 1.0$ & \\
\hline & 3 & $4.8 \pm 0.8$ & $3.0 \pm 0.4$ & $1.3 \pm 0.2$ & $31.0 \pm 8.5$ & $89.6 \pm 6.3$ & $10.5 \pm 3.5$ & \\
\hline & 4 & $3.5 \pm 0.9$ & $4.3 \pm 0.5^{\mathrm{A}}$ & $1.0 \pm 0.1$ & $8.5 \pm 2.3$ & $19.5 \pm 1.1$ & $1.7 \pm 0.5$ & \\
\hline \multirow[t]{4}{*}{ M50 } & 1 & $2.6 \pm 0.4$ & $2.0 \pm 0.7$ & $1.1 \pm 0.2$ & $2.1 \pm 5.7$ & $22.5 \pm 3.8$ & $6.2 \pm 2.4$ & $2 \pm 0.2$ \\
\hline & 2 & $3.8 \pm 0.6$ & $1.3 \pm 0.6$ & $1.0 \pm 0.2$ & $4.0 \pm 9.3$ & $27.6 \pm 3.3$ & $12.9 \pm 4.8$ & \\
\hline & 3 & $3.6 \pm 0.7$ & $2.0 \pm 0.5$ & $0.9 \pm 0.2$ & $2.2 \pm 5.6$ & $23.5 \pm 3.0$ & $6.3 \pm 1.9$ & \\
\hline & 4 & $3.6 \pm 0.9$ & $2.8 \pm 1.0^{\mathrm{A}, \mathrm{B}}$ & $1.2 \pm 0.3$ & $10.7 \pm 1.3$ & $19.8 \pm 1.0$ & $2.2 \pm 0.3$ & \\
\hline \multirow[t]{4}{*}{ GON } & 1 & $2.5 \pm 1.5$ & $1.5 \pm 0.5$ & $1.4 \pm 0.3$ & $39.8 \pm 6.6$ & $37.6 \pm 3.9$ & $14.9 \pm 3.3$ & $1.4 \pm 0.2$ \\
\hline & 2 & $4.0 \pm 1.0$ & $1.0 \pm 0.6$ & $1.4 \pm 0.3$ & $28.9 \pm 6.3$ & $29.4 \pm 3.7$ & $9.6 \pm 3.2$ & \\
\hline & 3 & $5.3 \pm 0.6$ & $2.0 \pm 0.4$ & $1.4 \pm 0.4$ & $30.1 \pm 9.6$ & $32.2 \pm 4.2$ & $10.5 \pm 4.7$ & \\
\hline & 4 & $5.0 \pm 0.7$ & $2.2 \pm 0.4^{B}$ & $0.8 \pm 0.2$ & $28.8 \pm 12.4$ & $29.8 \pm 6.6$ & $9.7 \pm 4.2$ & \\
\hline
\end{tabular}

Different letters indicate significant differences in the mean values of follicles recorded from $D 1$ to $D 4$ between groups ANOVA $p<0.05$ VOML: 3D colour ovary perfusion; VI: vascular index; FI: flow index; VFI: blood vessels and blood flow index (VFI)

(increased $\mathrm{MCV}$ and decreased $\mathrm{MCHC}$ ) were also associated with an electrolyte shift [34]. Glycerol is indeed a polar molecule which is known to alter the ionic strength and the dielectric constant of aqueous solutions [46]. In sheep, incubation of RBCs in glycerol media causes haemolysis due to a gradual increase of the intracellular glycerol concentration [47]. We can thus speculate that the RBC shape alterations observed in the high dose groups of this investigation may be caused by the glycerol permeating cell membrane following a concentration gradient [32] generated by the significant rise in glycerol circulating concentrations consequent to the dietary administration. Shape alterations of sheep RBCs reported in this trial are similar to those described in human glycerolized RBCs [34, 45], and might thus be associated with erythrocyte impaired functionality. In addition, when the average size of RBC's increases, they can fail to pass the capillaries in the microcirculation and be removed from the circulation [48]. All these changes might thus contribute to enhanced eryptosis. Further studies are needed to quantify the permeation of glycerol in the RBCs in vivo and to extend our knowledge on its osmotic effects. In the present study, in all groups but M100 the RBC shape alterations were not observed in blood samples collected $12 \mathrm{~h}$ after the glucogenic mixture administration. Nevertheless, reported results suggest the need to lowering the dose of the glycerol administered both as replacer of corn grain and as feed supplement, especially in long-lasting protocols.
By lowering the dose, however, the efficacy should be guaranteed. To verify whether the tested formulations were able to create a metabolic milieu suitable for the final follicular growth and thus for the conception period in the ewe, as described in previous studies [20], we compared the circulating concentrations of glycerol, glucose, insulin, urea and NEFA against those found in the M100 dose. This dose was taken from previous studies, being already evaluated for its effects on sheep metabolism and reproductive performance [8, 16, 18]. In the low dose groups, showing no alterations in plasma osmolality and RBC indices, the metabolic milieu was markedly different compared to that found in M100 (lower glycerol, glucose and insulin circulating concentrations, higher NEFA and urea circulating concentrations). In the high and moderate dose groups (G100, G75 and M75) the metabolic milieu elicited did not differ significantly from M100. However, plasma osmolality and RBC indices showed significant alterations compared to pre-administration values.

The medium dose groups, despite providing the same amount of energy $\left(0.6 \mathrm{Mcal} / \mathrm{d}\right.$ of $\left.\mathrm{NE}_{\mathrm{L}}\right)$, differed both for the metabolic response and for the $\mathrm{RBC}$ indices alterations observed. When this amount of energy was supplied by an association of glycerol and propylene glycol (M50), the metabolic milieu elicited was more similar to that found in M100 and no alterations in plasma osmolarity and $\mathrm{RBC}$ indices were observed. If the same amount of energy was supplied by glycerol alone (G50), the total dose of glycerol administered daily increased 
from 70 to $110 \mathrm{~mL}$. This higher dose was associated with $\mathrm{RBC}$ indices alterations (increased $\mathrm{MCHC}$ ). In addition, insulin concentrations were lower than those found in M100. The association of glycerol with propylene glycol seems thus a better option than glycerol alone. The hyperinsulinemic effect of propylene glycol is related to its glucogenic effect consequent to the increased absorption of propanol, propionate, and propanal originating from ruminal metabolism of propylene glycol [49]. This effect could be related to insulin resistance consequent to increased circulating levels of propylene glycol and propanol or to a decrease in the ratio of ketogenic to glucogenic metabolites in plasma [49].

However, if administered at high doses propylene glycol fermentation may produce sulphur-containing gases [50] and provoke negative effects, including ataxia, salivation, hyperventilation and depression [51]. At low doses, however, it allows reducing the amount of glycerol administered, and hence its osmotic effects, while acting synergistically in rising insulin concentrations.

The rise in glucose and insulin directly promotes follicular growth and development, mainly by altering FSHinduced effects on the synthesis of oestradiol by the granulosa cells, in accordance with the availability of glucose [52]. The follicle has indeed a functional insulinglucose-IGF-1 system which is affected by short-term nutritional treatments, and components of this metabolic system are nutritionally regulated in the follicle [53]. Moreover, elevated circulating concentrations of NEFA, which are indicative of negative energy balance, affect follicular growth and fertility by acting directly on the different ovarian cells, including the oocyte within the growing follicle, and may also affect the development of the fertilized oocyte, morula and early blastocyst [52]. Therefore, diets or metabolic states that favour high concentrations of NEFAs should be avoided during the cycle of conception and the early post-conception period [52]. In the same way, high levels of urea in blood have been associated with lower fertility due to a changed uterine environment and poor embryo viability [54-56].

The administration of M50 was associated with an increase in the mean circulating concentrations of glucose, although less marked than that found in M100, and insulin and with a decrease in NEFA circulating concentrations. Taken together, these results suggest that the M50 may represent a safe glucogenic formulation in ewes, being able to elicit comparable metabolic conditions as found at higher doses, but without altering RBC indices and plasma osmolality. The effects at ovary levels were thus compared with those of moderate doses of glucogenic formulation (M75 and G75) and with those provoked by eCG, having an FSH/LH-like effect. The use of gonadotropins is routinely incorporated into synchronization systems used in ewes to induce ovulation. The most commonly used product is eCG because, besides inducing ovulation, such hormone reduces variability in the onset of oestrus among treated animals and increases ovulation rate as a consequence of a greater follicular development [57]. In the present study, all glucogenic formulations were able to elicit an ovulatory response which did not differ significantly from what found in eCG treated ewes. It is remarkable that the high doses (G75 and M75) did not overcome the medium one (M50), which in contrast showed a numerically higher ovulation rate than the other treatments (n.s).

\section{Conclusions}

Glycerol is widely used as a feed supplement in ruminant nutrition. However, the results of the present study showed an alteration of RBC indices, and possibly of their functions, as a side effects of glycerol administration at moderate and high doses. Therefore, protocols foreseeing the administration of glycerol should be tested for their effects on $\mathrm{RBC}$ indices and functions. In general terms, medium doses of glucogenic mixtures should be preferred for flushing dairy ewes, as they proved to be effective at metabolic level without causing alterations in RBC indexes and possibly of their functionality.

\section{Methods}

The experiments were carried out at Bonassai research station of Agris Sardegna, located in north-western Sardinia, Italy $\left(40{ }^{\circ} \mathrm{N}, 8{ }^{\circ} \mathrm{E}, 32 \mathrm{~m}\right.$ a.s.l.). This study was divided into two experimental phases. Phase 1 aimed at determining the lowest doses of glycerol as a titration feeding trial able to modify ewe's metabolic status, as previously described using a high dose [20], without impacting on RBC indices. Glycerol was administered both alone and in combination with propylene glycol, as previously described $[10,19,20]$. Phase 2 aimed at assessing the effect of the administration of the glucogenic doses selected in Phase 1 on ovarian follicular population assessed by three-dimensional ovarian ultrasound scanning and oestradiol production during an induced follicular phase. The ewes enrolled in phase 1 and 2 were obtained from the experimental flock reared at the Agris research station. After the study, the ewes were released and returned to the experimental flock. Based on the research objective, the minimum sample size was estimated in order to obtain significantly reliable data on differences in glucose plasma levels. This estimation derived from the use of common methods for statistical evaluation, allowing to test the quality of different glucogenic-based nutritional treatments using the minimum number of animals. For this purpose, a power analysis was carried out using the statistical software $G$ * 
Power 3.1.9.2, setting the $\alpha$ error at 0.05 and the statistical power at 0.80 . The analysis showed that, with a total of 5 animals per group, there is an $81 \%$ chance of correctly rejecting the null hypothesis of absence of differences between groups.

\section{Phase 1}

\section{Animals and treatments}

The experiment was run during March-April 2019, within the anoestrus season described for this breed at this latitude. Twenty adult (3-7 years) and multiparous non-lactating Sarda dairy ewes were used. Glycerol and propylene glycol had a purity grade of $99.5-100 \%$ and complied with EU Reg. 231/2012 for food additives (E422 and E1520 for glycerol and propylene glycol, respectively; Farmalabor srl, Assago, Milano, Italy). Glycerol was administered alone (G groups: 90\% glycerol and $10 \%$ water; $\% \mathrm{v} / \mathrm{v})$ or in combination with propylene glycol (M groups: $70 \%$ glycerol, $20 \%$ propylene glycol, $10 \%$ water; $\% \mathrm{v} / \mathrm{v})$. Treatments were formulated in order to give $100,75,50$ and $25 \%$ of the amount of energy supplied in previous experiments $[10,20,21]$. Table 7 summarizes ingredient and nutrient composition of the dietary formulation along with estimated energy supplied to each group. A two-period design was used to allow comparisons between the eight formulations tested (M100, G100, M75, G75, M50, G50, M25, G25), with 4 days of treatment (period 1, groups M100, G100, M25, G25, $n=5$ per group), followed by 1 month of wash out and 4 days of treatment (period 2, groups M75, G75, M50, G50, $\mathrm{n}=5$ per group). Each ewe was randomly assigned to 2 treatment groups, one per period. Groups were homogeneous for body weight (BW; Table 7), measured before the morning meal by means of a digital scale for livestock.

Glucogenic formulations were administered b.i.d. for 4 days (D 1-4 of the experimental periods) at 08:00 in the morning and 19:00 in the evening, using a drench gun. This daily dosing schedule was set as close as possible to that adopted in previous experiments by our laboratories (twice daily, every $12 \mathrm{~h}$ e.g.) [10].

During each period, before starting the glucogenic treatment ( $\mathrm{D} 0$ of the experimental period), blood samples were collected at fasting (08:00). In addition, on D 3 of the experimental period, consecutive blood samples were collected at 8 time points, starting at fasting immediately before the morning administration of glucogenic mixture (08:00, 08:30, 09:00, 09:30, 10:00, 11:00, 12:00, 18:00). From.

D 0 to D 7, i.e. throughout the treatment periods, the sub-groups were kept indoors in separate pens. Indoor daily feeding consisted of $200 \mathrm{~g} /$ head of a pelleted concentrate individually fed at 08:00, plus c.a. $1500 \mathrm{~g} /$ head of ryegrass hay. On blood sampling day, the concentrate was fed immediately after the first bleeding. The pelleted concentrate was completely consumed by the animals. Water and mineral blocks were available ad libitum. During the wash out period, the ewes of both experimental subgroups were fed the same diet as above. Figure 3 shows the exact timing at which treatments, samplings and measurements were performed.

\section{Feedstuff composition}

The compound feed was a commercial pelleted formulation based on cereals and soybean meal, with a net energy content $\left(\mathrm{NE}_{\mathrm{L}}\right)$ of $1.43 \mathrm{Mcal} / \mathrm{kg}, 17 \%$ Crude protein (CP) and 32\% starch, on DM basis. The home-grown hay was a late-cut Italian ryegrass with $6.5 \% \mathrm{CP}$ and $75 \%$ $\mathrm{NDF}$ and a $\mathrm{NE}_{\mathrm{L}}$ content of $0.86 \mathrm{Mcal} / \mathrm{kg}$ on $\mathrm{DM}$ basis. The hay was chopped before feeding.

\section{Blood samplings and plasma osmolality determination}

On D 0 , in both periods, plasma concentrations of glycerol, glucose, insulin, NEFA, urea, plasma osmolality and, in whole blood, RBC indices were determined from samples drawn from jugular vein before morning feeding at 08:00. On D 3, plasma concentrations of glycerol, glucose, insulin, NEFA, urea, and plasma osmolality were also determined from eight consecutive samples, while $\mathrm{RBC}$ indices from two samples (at 08:00 and at 10:00). Repeated sampling on D 3 were collected after jugular cannulation. At each sampling, from each ewe, two blood samples were collected: one using $2-\mathrm{mL}$ vacuum collection tubes with glycolytic inhibitor $(5.0 \mathrm{mg}$ sodium fluoride, $4.0 \mathrm{mg}$ pot. ox. - Vacutainer Systems Europe; Becton Dickinson, MeylanCedex, France) for glucose assay; one using $2.0 \mathrm{~mL}$ vacuum collection whole blood tube with spray-coated $\mathrm{K}_{2}$ EDTA (Vacutainer Systems Europe; Becton Dickinson, MeylanCedex, France) for other metabolites, insulin and RBC indices determination. Immediately after recovery, samples were cooled to $4{ }^{\circ} \mathrm{C}$. $\mathrm{RBC}$ indices were determined within $2 \mathrm{~h}$ of blood collection. The other blood samples were centrifuged at $1500 \mathrm{~g}$ for $15 \mathrm{~min}$ at $4{ }^{\circ} \mathrm{C}$ degrees. Individual plasma was removed and stored in vial at $-20^{\circ} \mathrm{C}$ until assayed.

Plasma osmolality $(\mathrm{Osm} / \mathrm{kg})$ was measured using a freezing point osmometer (Osmomat 030, Gonotec, Berlin, Germany).

\section{Complete blood count (CBC)}

Haematological testing was integral to the interpretation of results to establish the safe amount of glycerol following the titration trial. Particular care was taken to prevent analytical biases responsible to affect blood sample diagnostic potentials. In light of the recommendations of the International Council for Standardization in Hematology (ICSH) the use of $\mathrm{K}_{2}$ EDTA (ethylene diamine tetracetic 
Table 7 Ingredient and nutrient composition of the dietary formulation along with estimated energy supplied

\begin{tabular}{|c|c|c|c|c|c|c|c|c|}
\hline \multirow[b]{2}{*}{ Group } & \multicolumn{2}{|l|}{ High doses } & \multicolumn{2}{|l|}{ Moderate doses } & \multicolumn{2}{|l|}{ Medium doses } & \multicolumn{2}{|l|}{ Low doses } \\
\hline & M100 & G100 & M75 & G75 & M50 & G50 & M25 & G25 \\
\hline BW & $53.3 \pm 2.0$ & $55.2 \pm 2.3$ & $51.5 \pm 1.7$ & $50.7 \pm 1.3$ & $49.0 \pm 2.0$ & $49.2 \pm 1.8$ & $49.0 \pm 2.0$ & $49.7 \pm 2.3$ \\
\hline Formulation & $\begin{array}{l}\text { Glycerol, Propylene } \\
\text { glycol, Water }\end{array}$ & $\begin{array}{l}\text { Glycerol, } \\
\text { Water }\end{array}$ & $\begin{array}{l}\text { Glycerol, Propylene } \\
\text { glycol, Water }\end{array}$ & $\begin{array}{l}\text { Glycerol, } \\
\text { Water }\end{array}$ & $\begin{array}{l}\text { Glycerol, Propylene } \\
\text { glycol, Water }\end{array}$ & $\begin{array}{l}\text { Glycerol, } \\
\text { Water }\end{array}$ & $\begin{array}{l}\text { Glycerol, Propylene } \\
\text { glycol, Water }\end{array}$ & $\begin{array}{l}\text { Glycerol, } \\
\text { Water }\end{array}$ \\
\hline Energy \% & $100 \%$ & $100 \%$ & $75 \%$ & $75 \%$ & $50 \%$ & $50 \%$ & $25 \%$ & $25 \%$ \\
\hline $\begin{array}{l}\text { Energy ( } \mathrm{NE}_{\mathrm{L}} \\
\text { Mcal/d) }\end{array}$ & 1.2 & 1.2 & 0.9 & 0.9 & 0.6 & 0.6 & 0.3 & 0.3 \\
\hline Glycerol (mL) & 140 & 220 & 105 & 169 & 70 & 110 & 35 & 55 \\
\hline $\begin{array}{l}\text { Propylene } \\
\text { Glycol (mL) }\end{array}$ & 40 & & 30 & & 20 & & 10 & \\
\hline Water (mL) & 20 & 22 & 15 & 17 & 10 & 11 & 5 & 5 \\
\hline Total (mL) & 200 & 242 & 150 & 186 & 100 & 121 & 50 & 60 \\
\hline$\%$ DM & 22.9 & 27.4 & 18.2 & 22.5 & 12.9 & 15.9 & 6.9 & 8.6 \\
\hline
\end{tabular}

acid) as anticoagulant was preferred, due to the less pronounced osmotic effect on blood cells than that exerted by $\mathrm{K}_{3}$ EDTA $[58,59]$. O The same skilled veterinary surgeon collected blood samples in vacuum tubes until filled to the correct volume and gently mixed 5 to 10 times to allow complete interaction with the anticoagulants and to prevent clotting [58], before storage in the upright position and cooling to $4{ }^{\circ} \mathrm{C}$. According to the recommendations to preserve diagnostic samples in the preanalytical phase (ICSH, 1993), all the samples were transported refrigerated to the laboratory where individual haematological profiles were assessed within $2 \mathrm{~h}$ of blood sampling.

In brief, $15 \mu \mathrm{L}$ of each whole blood sample were needed for the determination of haematological parameters through capillary analysis based on tri-angle scattering and chemical dying read through flow cytometry technology. The following parameters were determined using an automatic cell counter instrument (Hematology analyzer Alcyon Mindray BC-5000, Shenzhen, China): white blood cell count (WBC), red blood cell (RBC), hemoglobin (HGB), hematocrit (HCT), mean corpuscular volume $(\mathrm{MCV})$, mean corpuscular hemoglobin $(\mathrm{MCH})$, mean corpuscular hemoglobin concentration $(\mathrm{MCHC})$, red blood cell distribution width (RDW-SD), platelet
(PLT), neutrophil granulocytes (Neu), lymphocytes (Lym), monocytes (Mon), eosinophil granulocytes (Eos), basophil granulocytes (Bas), mean platelet volume (MPV), platelet distribution width (PDV) and plateletcrit (PCT). Both absolute and relative values of leukocytes were analyzed for each sample. For the purposes of the present study, only the following RBC indices [60] were considered: 1) MCV: defines the size of the red blood cells and is expressed as femtoliters $\left.\left(10^{-15} ; \mathrm{fl}\right) ; 2\right) \mathrm{MCH}$ : quantifies the amount of haemoglobin per red blood cell and is expressed in picograms (pg); 3) MCHC: indicates the amount of haemoglobin per unit volume. In contrast to $\mathrm{MCH}, \mathrm{MCHC}$ correlates the haemoglobin content with the volume of the cell and it is expressed as $\mathrm{g} / \mathrm{L}$ of RBCs; 4) RDW-SD: represents the coefficient of variation of the RBC volume distribution (size) and is expressed as femtoliters. It is a good indicator of the degree of anisocytosis.

In addition, from each blood sample processed for $\mathrm{CBC}$, whole blood smears were carried out for microscopic examination of blood cell morphology. In particular, microscopic examination (200X; Olympus BX41, Olympus Italia Srl, Segrate, Milano, Italy) of whole blood smear aimed to support the automatic reading obtained at haematology analyser, by excluding the presence of accidental platelets clumping or RBC rouleaux formation

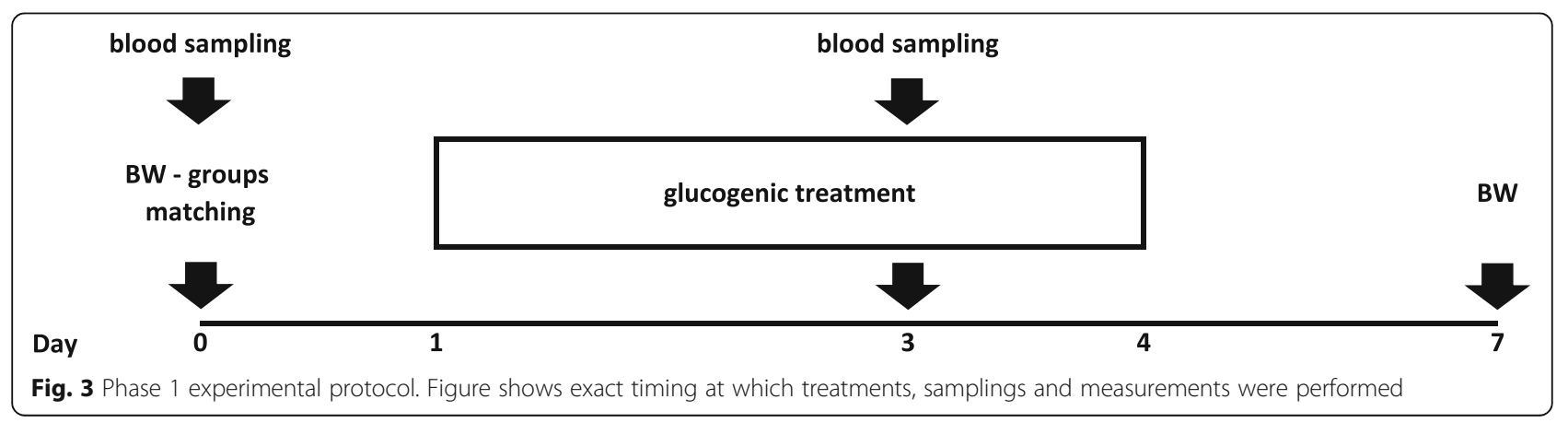


and therefore to consider the samples as diagnostic for the purpose of the investigation.

\section{Metabolites}

Plasma samples were measured in duplicate. Glycerol concentration was measured in a single assay by colorimetric method using a commercial Free Glycerol Assay Kit (Cell Biolabs, Inc., USA), with glycerol standards in the concentration range of $0 \mu \mathrm{M}-400 \mu \mathrm{M}$. The kit measures free, endogenous glycerol by a coupled enzymatic reaction system. The glycerol is phosphorylated and oxidized, producing hydrogen peroxide which reacts with the kit's Colorimetric Probe (absorbance maxima of 570 $\mathrm{nm})$. The analytical detection limit was $5 \mu \mathrm{M}$.

Glucose, NEFA, and urea were measured using commercial kit and BS-200 Mindray clinical chemistry analyzer. We used Serum I Normal (Wako) and Serum II Abnormal (Wako) as multi control for each measured parameter. Glucose concentrations were determined in a single assay by liquid enzymatic colorimetric method (GOD-POD) (Real Time kit) with a glucose standard of $100 \mathrm{mg} / \mathrm{dL}$ for calibration. Intra-assay CV values were $1.1 \%$. NEFA and urea concentrations were measured in multiple assays by enzymatic endpoint method (Diagnostic Systems kit), with a NEFA standard of $1 \mathrm{mmol} / \mathrm{L}$ and a urea standard of $50 \mathrm{mg} / \mathrm{dL}$ for calibration. NEFA intra-assay and interassay CV values were 1.07 and $0.98 \%$, respectively. UREA intra-assay and interassay CV values were 1.7 and $1.6 \%$, respectively.

\section{Insulin}

ELISA assays were performed using the Personal Lab Adaltis (Adaltissrl, Rome, Italy), which is a tool that performs automated ELISA protocols. Insulin concentration was measured in duplicate using a commercial Ovine Insulin ELISA Kit (Mercodia developing diagnostics, Germany) which is a solid-phase ELISA based on the direct sandwich technique. The kit is calibrated against an in-house reference preparation of ovine insulin, and it has been previously used for insulin determination in ovine plasma $[61,62]$. The mean ovine insulin concentrations of the six reference solutions were $0,0.05,0.15$, $0.5,1.5$, and $3 \mathrm{mg} / \mathrm{L}$. The recovery on addition was $94-$ $114 \%$ (mean 103\%). The analytical sensitivity was 0.025 $\mathrm{mg} / \mathrm{L}$ and the intra-assay and interassay $\mathrm{CV}$ values were $<7 \%$.

\section{Phase 2}

\section{Animals and treatments}

The experiment was run during August-September 2019, within the natural breeding season described for this breed at this latitude. Twenty adults (2-7 years) non-lactating Sarda dairy ewes were used. The glucogenic formulations to be tested (G75, M75, M50) were chosen on the basis of the results of Phase 1 . Control ewes (GON group) received $150 \mathrm{~mL}$ of water twice daily simultaneously to treatment administration. Water was administered using a drench gun. The four experimental groups were homogeneous for body weight (BW, mean $\mathrm{Kg} \pm \mathrm{SE} ; \mathrm{GON} 43.6 \pm 3.7, n=5 ; \mathrm{G75} 43.8 \pm 1.8, \mathrm{n}=5$; M50 44.2 $\pm 1.9, \mathrm{n}=5 ;$ M75 43.4 $\pm 1.2, \mathrm{n}=5 ; P=0.996)$.

Glucogenic treatments were administered following an oestrus synchronization protocol. In brief (Fig. 4), synchronization was induced in all the animals by i.m. injection of PGF $2 \alpha$ analogue (PGF Veyx $0,250 \mathrm{mg} / \mathrm{mL}$, Veyx Pharma GMBH, Schwarzenborn, Germany), administered twice, at $13 \mathrm{~d}$ interval (first injection at day 10 , second at day 3). Simultaneously to the second PGF2 $\alpha$ injection (D 3, 08:00) control ewes (GON group) were injected intramuscularly with $200 \mathrm{IU}$ of eCG (Folligon, MSD Animal Health Srl, Segrate, Italy).

From D 0 to D 4, i.e. throughout the treatment periods, the groups were kept indoors in separate pens. Indoor daily feeding consisted of $200 \mathrm{~g} / \mathrm{head}$ of a commercial pelleted feed and $150 \mathrm{~g} /$ head of maize grain divided in two equal meals (08:00 and 15:00) and individually fed in the milking parlour and $1500 \mathrm{~g} / \mathrm{head}$ of hay fed in the afternoon. On the blood sampling day, the morning meal based on compound feeds was administered immediately after the first blood sampling. Water and mineral blocks were available ad libitum. Concentrates were completely consumed by the animals.

\section{Feedstuff composition}

Compound feeds and hay administered in the phase 2 were the same as those of phase 1 . The whole maize grain had CP content of $7.80 \%$, starch level of $69.9 \%$ and a $\mathrm{NE}_{\mathrm{L}}$ of $2.00 \mathrm{Mcal} / \mathrm{kg}$ on DM basis.

\section{Determination of oestradiol plasma concentration}

On day 5 of the experimental period ( $48 \mathrm{~h}$ after the second PGF2 $\alpha$ administration), blood samples were drawn from jugular vein at fasting at 08:00. Blood samples were collected using 10-mL vacuum collection tubes (BD Vacutainer ${ }^{\oplus}$ Rapid Serum Tube - Vacutainer Systems Europe; Becton Dickinson, MeylanCedex, France) for oestradiol assay. Immediately after recovery, blood samples were cooled at $4{ }^{\circ} \mathrm{C}$ and centrifuged at $1500 \mathrm{~g}$ for 15 min. Serum was removed and stored at $-20^{\circ} \mathrm{C}$ until assayed.

Samples were measured in duplicate. Concentrations of oestradiol were measured after sample extraction by using a highly sensitive commercial enzimoimmunoassay kit for quantitative determination of estradiol-17 $\beta$ (Demeditec Diagnostics GmbH, Kiel-Wellsee, Germany). Sensitivity of the assay was $1.4 \mathrm{pg} / \mathrm{mL}$ and intra-assay variation coefficient was $5.7 \%$. 


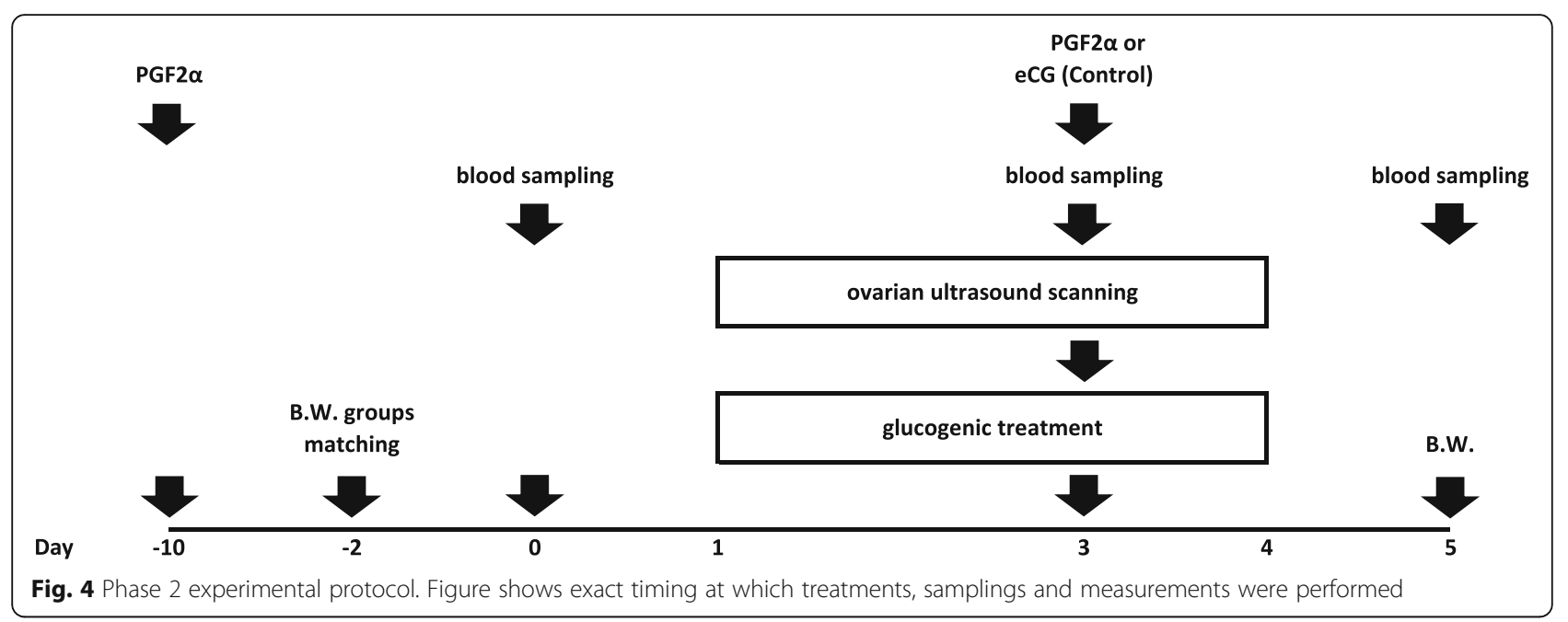

\section{Ovarian 3D ultrasound scanning}

From day 1 to day 4, ovarian follicular population was studied daily using trans-vaginal 3D ultrasonography. Ultrasonographic examinations were carried out using a Mylab-alpha (Esaote, Italia) fitted to an endocavitary transducer $(8-11 \mathrm{MHz})$. Each ovarian follicular population was scanned using both conventional 2D-US, 3DUS and 3D Power Doppler Ultrasound (3D PD-US) image acquisition methods by an experienced sonographer. 3D power Doppler were performed to evaluate the ovary perfusion.

The images were recorded as digital files for later examination and the ovarian follicular population vascular index (VI), flow index (FI), blood vessels and blood flow index (VFI) by three-dimensional Doppler histogram were calculated.

Thereafter, on day 14 ovulation rates were determined by counting the corpora lutea present in each ovary by transrectal ultrasonography with a real-time B-mode scanner (Aloka102 SSD 500; Aloka Co., Tokyo, Japan) fitted with a $7.5 \mathrm{MHz}$ linear-array probe.

\section{Statistical analyses}

Results are expressed as mean values (mean $\pm \mathrm{SE}$ ) or median values (median and range) and the differences were considered to be statistically significant at $P<0.05$.

Differences in ewe's body weight at the beginning and at the end of the glucogenic-treatment period in phase 1 and 2 were analysed by a mono-factorial GLM.

The distribution of variables at Day 0 was assessed by the Kolmogorov-Smirnov test.

In phase 1, longitudinal data of plasma glycerol, glucose, insulin, NEFA and urea in the consecutive samples collected on day 3 (during treatment period) were analysed by a GLM UNIANOVA model in SPSS (IBM Corp. Released 2016. IBM SPSS Statistics for Windows, Version 24.0. Armonk, NY: IBM Corp) with treatment, sampling hour and their first-order interactions as fixed effects. As post-hoc test, for plasma glycerol, glucose, insulin, NEFA and urea, a one-tailed Dunnett's test was used to highlight negative or positive differences, in respect of M100 group, as appropriate.

In addition, mean circulating concentration of plasma glycerol, glucose, insulin, NEFA and urea on day 3 (during treatment period) were analysed by a GLM UNIANOVA model in SPSS with treatment as fixed effects. As post-hoc test, a one-tailed Dunnett's test was used to highlight negative or positive differences, respect to M100 group, as appropriate.

A SPSS GLM UNIANOVA model was also used to highlight changes among groups on plasma osmolality, $\mathrm{RBC}$ indices and circulating concentrations of analysed metabolites and hormones between day 0 and day 3 .

Longitudinal data of plasma osmolality in the consecutive samples collected on day 3 (during treatment period) were analysed by a GLM UNIANOVA model in SPSS with treatment, sampling hour and their first-order interactions as fixed effects. A post-hoc test Tukey's test was used to highlight differences between and among groups.

A SPSS GLM UNIANOVA model was also used to evaluate within groups the effect of nutritional treatments on RBC indices before and $2 \mathrm{~h}$ after treatment administration on D 3.

Finally, the relationship between treatments administrated, concentration of metabolites and hormones and the relationship between treatments and RBC indices at two hours post treatment, were evaluated by Pearson's correlation analysis. The strength of the correlation was considered poor for $r$ values ranging from \pm 0.1 to \pm 0.3 , fair for $\mathrm{r}$ values ranging from \pm 0.3 to \pm 0.5 , moderately strong for $\mathrm{r}$ values ranging from \pm 0.6 to \pm 0.8 and very strong for $\mathrm{r}$ values ranging from \pm 0.8 to \pm 1 [63].

In phase 2, longitudinal data on follicular population, ovarian vascularity and flow index and their relationship, 
as evaluated by ultrasound scanning, were analysed by a GLM UNIANOVA model in SPSS with treatment, day and their first-order interactions as fixed effects. As post-hoc test, Fisher LSD test was used to highlight differences between groups. A One-way ANOVA test was used to compare ovulation rate and oestradiol blood levels between the different experimental groups.

\section{Supplementary information}

Supplementary information accompanies this paper at https://doi.org/10. 1186/s12917-020-02418-z.

Additional file 1: Figure 1. - Concentrations-time data of the analysed metabolites and hormones on day 3 of phase 1. Asterisks indicate significant differences between M100 group and other groups $(P<0.05)$.

\section{Abbreviations}

RBC: red blood cell; eCG: equine chorionic gonadotrophin; DM: dry matter; MCV: Mean corpuscular volume; MCH: Mean corpuscular hemoglobin; MCHC: Mean corpuscular hemoglobin concentration; RDW-SD: red blood cell distribution width; NEFA: Non-esterified fatty acids; VOML: 3D colour ovary perfusion; VI: Vascular index; FI: Flow index; VFI: Blood vessels and blood flow index; BW: Body weight; $\mathrm{NE}_{\mathrm{L}}$ : Net energy content; $\mathrm{CBC}$ : Complete blood count

\section{Acknowledgements}

The authors gratefully thank AGRIS staff for the technical assistance and for caring the experimental animals.

\section{Authors' contributions}

$C P, F D S$ and VP collected the data, performed the analyses and provided intellectual input. CP and GM performed the statistical analyses. MGC performed the complete blood count analyses. ABF performed the three-dimensional ovarian ultrasound scanning. AGB performed the analyses and provided intellectual input. MD, MG and GM collected the data, supervised the management of the experimental animals and provided intellectual inputs. FB and GM conceived and designed the study. FB drafted the manuscript. All authors contributed to the interpretation of the data and the writing and editing of the manuscript. The author (s) read and approved the final manuscript.

\section{Funding}

This study was financed by a doctoral grant from the Italian Ministry of Education, University and Research (Programma Operativo Nazionale Ricerca e Innovazione 2014-2020 - CCI 2014IT16M2OP005 - Fondo Sociale Europeo, Azione I.1 "Dottorati Innovativi con caratterizzazione Industriale). The funding institution financed laboratory analysis, the dietary treatments, and FDS. The funding institution had no role in the design of the study; in the collection, analysis, and interpretation of data; or in the writing of the manuscript.

\section{Availability of data and materials}

The datasets used and analysed in the current study are available from the corresponding author on reasonable request.

\section{Ethics approval and consent to participate}

The animal protocol and the implemented procedures described below are in accordance with the ethical guidelines in force at Agris and the University of Sassari, in compliance with the European Union Directive 86/609/EC and the recommendation of the Commission of the European Communities 2007/526/EC. 2.1. The procedure was authorized by the Italian Ministry for Health (n. 705/2019-PR).

\section{Consent for publication}

Not applicable.

\section{Competing interests}

The authors declare that they have no competing interests.

\section{Author details}

${ }^{1}$ Department of Veterinary Medicine, University of Sassari, Via Vienna 2, 07100 Sassari, Italy. ${ }^{2}$ Universidad Alfonso X el Sabio, Campus de Villanueva de la Cañada, Avd. Universidad 1, 28040 Madrid, Spain. ${ }^{3}$ Comparative Physiology Group, SGIT-INIA, Av. Puerta de Hierro s/n, 28040 Madrid, Spain. ${ }^{4}$ AGRIS Sardegna, Loc. Bonassai, 07100 Sassari, Italy.

Received: 6 April 2020 Accepted: 8 June 2020

Published online: 22 June 2020

\section{References}

1. Salami SA, Valenti B, O'Grady MN, Kerry JP, Mattioli S, Licitra G, et al. Influence of dietary cardoon meal on growth performance and selected meat quality parameters of lambs, and the antioxidant potential of cardoon extract in ovine muscle homogenates. Meat Sci. 2019;153(7):126-34.

2. Kholif AE. Glycerol use in dairy diets: a systemic review. Anim Nutr. 2019; 5(3):209-16. Available from https://doi.org/10.1016/j.aninu.2019.06.002.

3. EFSA ANS Panel (EFSA Panel on Food Additives and Nutrient Sources added to Food), Mortensen A, Aguilar F, Crebelli R, Di Domenico A, Dusemund B, Frutos MJ, Galtier P, Gott D, Gundert-Remy U, Leblanc JC, Lindtner O, Moldeus P, Mosesso P, Parent-Massin D, Oskarsson A, Stankovic I, Waalkens-Berendsen I, Woutersen RA, Wright M, Younes M, Boon P, Chrysafidis D, Gürtler R, Tobback $P$, Rincon AM, Tard A, Lambré C. Scientific opinion on the re-evaluation of glycerol (E 422) as a food additive. EFSA Journal. 2017; 15( 3):4720, 64 pp. https://doi.org/10.2903/j.efsa.2017.4720.

4. Younes $M$, Aggett $P$, Aguilar F, Crebelli R, Dusemund B, Filipič M, et al. Reevaluation of propane-1,2-diol (E 1520) as a food additive. EFSA J. 2018;16(4):1-40.

5. Van Cleef EHCB, Uwituze S, Alvarado-Gilis CA, Miller KA, Van Bibber-Krueger $\mathrm{CL}$, Aperce CC, et al. Elevated concentrations of crude glycerin in diets for beef cattle: feedlot performance, carcass traits and ruminal metabolism. J Anim Sci. 2019;97(10):4341-8

6. Gunn PJ, Neary MK, Lemenager RP, Lake SL. Effects of crude glycerin on performance and carcass characteristics of finishing wether lambs. J Anim Sci. 2010;88(5):1771-6.

7. Almeida MTC, Paschoaloto JR, Perez HL, Carvalho VB, Homem Junior AC, Favaro $V R$, et al. Effect of adding crude glycerine to diets with feed additives on the feed intake, ruminal degradability, volatile fatty acid concentrations and in vitro gas production of feedlot Nellore cattle. J Anim Physiol Anim Nutr (Berl). 2019; 103(4):988-96. Available from https://doi.org/10.1111/jpn.13105.

8. Khattab MSA. Glycerol as feedstuff for ruminant. Sci Int. 2015;3(3):90-4 Available from: http://scienceinternational.com/abstract.php?doi=sciintl.2015.90.94.

9. Carvalho VB, Leite RF, Almeida MTC, Paschoaloto JR, Carvalho EB, Lanna DPD, et al. Carcass characteristics and meat quality of lambs fed high concentrations of crude glycerin in low-starch diets. Meat Sci. 2015;110(10): 285-92. Available from: https://doi.org/10.1016/j.meatsci.2015.08.001.

10. Berlinguer F, Gonzalez-Bulnes A, Spezzigu A, Contreras-Solis I, Succu S, McNeilly AS, et al. Effect of aging on follicular function may be relieved by exogenous gonadotropin treatment in a sheep model. Reproduction. 2012; 144(2):245-55.

11. Novais-Eiras D, de Carvalho GGP, Leite LC, Eiras CE, de Freitas JE, de Freitas Júnior JE, dos Santos Pina D, et al. Crude glycerin in the feed supplementation of lactating goats on pasture. Small Rumin Res 2018;168(11):39-46.

12. Polizel DM, Susin I, Gentil RS, Ferreira EM, de Souza RA, Freire APA, et al. Crude glycerin decreases nonesterified fatty acid concentration in ewes during late gestation and early lactation. J Anim Sci. 2017;95(2):875-83.

13. Thoh D, Pakdeechanuan $P$, Chanjula P. Effect of supplementary glycerin on milk composition and heat stability in dairy goats. Asian Australas J Anim Sci. 2017;30(10):1711-7.

14. Webb R, Buratini J, Hernandez-Medrano JH, Gutierrez CG, Campbell BK. Follicle development and selection: past, present and future. Anim Reprod. 2016;13(3):234-49.

15. Gutierrez CG, Ferraro S, Martinez V, Saharrea A, Cortez C, Lassala A, et al. Increasing ovulation quota: more than a matter of energy. Acta Sci Vet. 2011;39(SUPPL. 1):305-16.

16. de Andrade GP, de Carvalho FFR, Batista ÂMV, Pessoa RAS, da Costa CA, Cardoso $D B$, et al. Evaluation of crude glycerin as a partial substitute of corn grain in growing diets for lambs. Small Rumin Res. 2018;165(September 2017):41-7.

17. Sá HCM, Borges I, Macedo Junior GDL, Santos FS, Cavalcanti LFL, Alvarenga FAP, et al. Evaluation of dairy sheep lambs supplemented with crude glycerin conveyed in water during pregnancy and lactation. Semin Agrar. 2017;38(4):2681-90. 
18. Polizel DM, Susin I, Gentil RS, et al. Crude glycerin decreases nonesterified fatty acid concentration in ewes during late gestation and early lactation. J Anim Sci. 2017;95(2):875-83. https://doi.org/10.2527/jas.2016.0999.

19. Letelier C, Mallo F, Encinas T, Ros JM, Gonzalez-Bulnes A. Glucogenic supply increases ovulation rate by modifying follicle recruitment and subsequent development of preovulatory follicles without effects on ghrelin secretion. Reproduction. 2008;136(1):65-72.

20. Porcu C, Pasciu V, Succu S, Baralla E, Manca MEE, Serra E, et al. Glucogenic treatment creates an optimal metabolic milieu for the conception period in ewes. Domest Anim Endocrinol. 2017;59:105-15. Available from: https://doi. org/10.1016/j.domaniend.2016.12.003.

21. Porcu C, Manca C, Cabiddu A, Dattena M, Gallus M, Pasciu V, et al. Effects of short-term administration of a glucogenic mixture at mating on feed intake, metabolism, milk yield and reproductive performance of lactating dairy ewes. Anim Feed Sci Technol. 2018;243(June):10-21. Available from https://doi.org/10.1016/j.anifeedsci.2018.06.012.

22. Scaramuzzi RJ, Brown HM, Dupont J. Nutritional and metabolic mechanisms in the ovary and their role in mediating the effects of diet on folliculogenesis: a perspective. Reprod Domest Anim. 2010;45(Suppl 3):3241 Available from: http://www.ncbi.n/m.nih.gov/pubmed/24417197.

23. Molle G, Landau S, Branca A, Sitzia M, Fois N, Ligios S, et al. Flushing with soybean meal can improve reproductive performances in lactating Sarda ewes on a mature pasture. Small Rumin Res. 1997;24:157-65.

24. Branca A, Molle G, Sitzia M, Decandia M, Landau S. Short-term dietary effects on reproductive wastage after induced ovulation and artificial insemination in primiparous lactating Sarda ewes. Anim Reprod Sci. 2000; 58(2):59-71.

25. Martinez-Ros P, Gonzalez-Bulnes A. Efficiency of CIDR-Based Protocols Including GnRH Instead of eCG for Estrus Synchronization in Sheep. Animals (Basel). 2019;9(4):146. https://doi.org/10.3390/ani9040146.

26. Krehbiel CR. Ruminal and physiological metabolism of glycerin. J Anim Sci. 2008;86:392

27. Werner Omazic A, Kronqvist C, Zhongyan L, Martens H, Holtenius K. The fate of glycerol entering the rumen of dairy cows and sheep. J Anim Physio Anim Nutr (Berl). 2015;99(2):258-64.

28. Ferraro SM, Mendoza GD, Miranda LA, Gutiérrez CG. In vitro ruminal fermentation of glycerol, propylene glycol and molasses combined with forages and their effect on glucose and insulin blood plasma concentrations after an oral drench in sheep. Anim Feed Sci Technol. 2016; 213:74-80. Available from: https://doi.org/10.1016/j.anifeedsci.2016.01.010.

29. Gleeson M, Maughan RJ, Greenhaff PL. Comparison of the effects of preexercise feeding of glucose, glycerol and placebo on endurance and fuel homeostasis in man. Eur J Appl Physiol Occup Physiol. 1986;55(6):645-53.

30. Freund BJ, Montain SJ, Young AJ, Sawka MN, DeLuca JP, Pandolf KB, et al. Glycerol hyperhydration: hormonal, renal, and vascular fluid responses. J Appl Physiol. 1995;76(6):2069-77.

31. Montner P, Stark DM, Riedesel ML, Murata G, Robergs R, Timms M, et al. Preexercise glycerol hydration improves cycling endurance time. Int J Sports Med. 1996;17(1):27-33.

32. Valeri CR, Ragno G. Cryopreservation of human blood products. Transfus Apher Sci. 2006;34(3):271-87. https://doi.org/10.1016/j.transci.2005.11.010.

33. Gallagher PG. Disorders of red cell volume regulation. Curr Opin Hematol. 2013; 20(3):201-07. https://doi.org/10.1097/MOH.0b013e32835f6870.

34. Bizjak DA, Jungen P, Bloch W, Grau M. Cryopreservation of red blood cells: effect on rheologic properties and associated metabolic and nitric oxide related parameters. Cryobiology. 2018;84(august):59-68. Available from https://doi.org/10.1016/j.cryobiol.2018.08.001.

35. Hoffmann EK, Lambert IH, Pedersen SF. Physiology of cell volume regulation in vertebrates. Physiol Rev. 2009;89(1):193-277.

36. Narla J, Mohandas N. Red cell membrane disorders. Int J Lab Hematol. 2017; 39 Suppl 1:47-52. https://doi.org/10.1111/ijlh.12657.

37. Glogowska E, Gallagher PG. Disorders of erythrocyte volume homeostasis. Int J Lab Hematol. 2015;37 Suppl 1(01):85-91. https://doi.org/10.1111/ijlh.12357.

38. Dimauro C, Bonelli P, Nicolussi P, Rassu SPG, Cappio-Borlino A, Pulina G. Estimating clinical chemistry reference values based on an existing data set of unselected animals. Vet J. 2008;178(2):278-81.

39. Baskurt OK, Meiselman HJ. Data reduction methods for ektacytometry in clinical hemorheology. Clin Hemorheol Microcirc. 2013;54(1):99-107.

40. Roudier N, Verbavatz J-M, Maurel C, Ripoche P, Tacnet F. Evidence for the presence of aquaporin-3 in human red blood cells. J Biol Chem. 1998; 273(14):8407-12
41. Carlsen A, Wieth JO. Glycerol transport in human red cells. Acta Physiol Scand. 1976;97(4):501-13.

42. Meyerstein N, Mazor D, Etzion Z, Yagil R. Permeability of erythrocytes to glycerol and its acylated derivatives in the camel and dog. Comp Biochem Physiol A Physiol. 1978;61(2):261-5.

43. Scott LA. Diffusion Across a Sheep Red Blood Cell Membrane. In Tested studies for laboratory teaching, Volume 14, (C. A. Goldman, Editor). Proceedings of the 14th Workshop/Conference of the Association for Biology Laboratory Education (ABLE); 1993, pp. 115-140.

44. Lahmann JM, Benson JD, Higgins AZ. Concentration dependence of the cell membrane permeability to cryoprotectant and water and implications for design of methods for post-thaw washing of human erythrocytes. Cryobiology. 2018:80:1-11. https://doi.org/10.1016/j.cryobiol.2017.12.003.

45. Pallotta V, D'Amici GM, D’Alessandro A, Rossetti R, Zolla L. Red blood cell processing for cryopreservation: From fresh blood to deglycerolization. Blood Cells Mol Dis. 2012;48(4):226-32. Available from: https://doi.org/10. 1016/j.bcmd.2012.02.004.

46. Farnum M, Zukoski CF. Effect of glycerol on the interactions and solubility of bovine pancreatic trypsin inhibitor. Biophys J. 1999;76(5):2716-26.

47. Zou C-G, Agar NS, Jones GL. Haemolysis of human and sheep red blood cells in glycerol media: the effect of $\mathrm{pH}$ and the role of band 3. Comp Biochem Physiol Part A Mol Integr Physiol. 2000 Nov;127(3):347-53.

48. Almac $E$, Ince $C$. The impact of storage on red cell function in blood transfusion. Best Pract Res Clin Anaesthesiol. 2007;21(2):195-208.

49. Kristensen NB, BML R. Ruminal and intermediary metabolism of propylene glycol in lactating Holstein cows. J Dairy Sci. 2007;90(10):4707-17 [cited 2020 Mar 9]. Available from https://doi.org/10.3168/jds.2007-0295.

50. Trabue S, Scoggin K, Tjandrakusuma S, Rasmussen MA, Reilly PJ. Ruminal fermentation of propylene glycol and glycerol. J Agric Food Chem. 2007; 55(17):7043-51.

51. Nielsen NI, Ingvartsen KL. Propylene glycol for dairy cows: a review of the metabolism of propylene glycol and its effects on physiological parameters, feed intake, milk production and risk of ketosis. Anim Feed Sci Technol. 2004;115(3-4):191-213.

52. Dupont J, Scaramuzzi RJ, Reverchon M. The effect of nutrition and metabolic status on the development of follicles, oocytes and embryos in ruminants. Animal. 2014;8(7):1031-44. https://doi.org/10.1017/ S1751731114000937.

53. Dupont J, Reverchon M, Bertoldo MJ, Froment P. Nutritional signals and reproduction. Mol Cell Endocrinol. 2014;382:527-37.

54. Bishonga C, Robinson JJ, Mcevoy TG, Findlay P, Aitken RP, Robertson I. Excess dietary urea intake in ewes and its effect on ovulation rate and embryo development. Jpn J Vet Res. 1996;44(3):139-51.

55. McEvoy TG, Robinson JJ, Aitken RP, Findlay PA, Robertson IS. Dietary excesses of urea influence the viability and metabolism of preimplantation sheep embryos and may affect fetal growth among survivors. Anim Reprod Sci. 1997;47(1):71-90.

56. Elrod CC, Butler WR. Reduction of fertility and alteration of uterine $\mathrm{pH}$ in heifers fed excess ruminally degradable protein. J Anim Sci. 1993;71(3):694-701.

57. Wildeus S. Current concepts in synchronization of estrus: Sheep and goats. J Anim Sci. 2000;77(E-Suppl):1.

58. Lippi G, Salvagno GL, Montagnana M, Banfi G, Guidi GC. Evaluation of different mixing procedures for K2 EDTA primary samples on hematological testing. Lab Med. 2007:38(10):723-5.

59. Bull BS, Caswell M, Ernst E, Jou JM, Kallner A, Koepke JA, et al. ICSH recommendations for measurement of erythrocyte sedimentation rate. J Clin Pathol. 1993:46(3):198-203. https://doi.org/10.1136/jcp.46.3.198.

60. Sarma P. In: HJ HWWHK, editor. Red Cell Indices Clinical Methods: The History, Physical, and Laboratory Examinations. Boston: Butterworths; 1990.

61. Melendez P, Krueger T, White J, Badinga L, Verstegen J, Donovan GA, et al. Effect of ghrelin in dry matter intake and energy metabolism in prepartum sheep: a preliminary study. Theriogenology. 2006;66(8):1961-8.

62. Mahjoubi E, Amanlou H, Mirzaei-Alamouti HR, Aghaziarati N, Hossein Yazdi M, Noori GR, et al. The effect of cyclical and mild heat stress on productivity and metabolism in Afshari lambs. J Anim Sci. 2014;92(3):1007-14.

63. Chan YH. Biostatistics 104: correlation analysis. Singap Med J. 2003;44(12):614-9.

\section{Publisher's Note}

Springer Nature remains neutral with regard to jurisdictional claims in published maps and institutional affiliations. 